\title{
Long-term physical morbidity in ARDS survivors
}

\author{
Sangeeta Mehta ${ }^{1,3^{*}}$ and Pedro Povoa ${ }^{2}$
}

C 2016 Springer-Verlag Berlin Heidelberg and ESICM

Survivors of ARDS have significant morbidity. Thanks to innovative investigators, we have started to accumulate robust data regarding long-term physical and neuropsychological consequences of ARDS. These prognostic data are important for clinicians, patients and family members; and will be invaluable in the development of ICU and post-ICU multi-component interventions which will reduce short- and long-term morbidity.

Herridge and her colleagues have led the way in ICU outcomes research. Their data paint a vivid and startling picture of profound-primarily extra-pulmonary-disability in survivors of critical illness [1-3]; and depressive symptoms in caregivers [4]. In ARDS survivors they showed exercise limitation, physical and psychological sequelae, decreased physical quality of life, and increased costs and use of healthcare services persisting over 5 years $[1,2]$. More recently their Towards RECOVER Study described outcomes of 391 ICU survivors mechanically ventilated for at least 7 days [3]. Using recursive partitioning modeling, the authors could stratify patients into four disability risk groups based on age and ICU length of stay (LOS); these four groups determine 1-year recovery and healthcare utilization independent of admitting diagnosis and illness severity. Patients older than 66 years with ICU LOS longer than 2 weeks sustained the worse disability and had $40 \% 1$-year mortality. They subsequently validated the four risk groups in their ARDS cohort [5].

In an article recently published in Intensive Care Medicine, Pfoh and her colleagues contribute valuable data to the existing literature on ICU outcomes, with 5-year follow-up data from the Improving Care of All Patients (ICAP) study [6]. The ICAP study followed 222 acute

*Correspondence: Geeta.mehta@utoronto.ca

${ }^{3}$ Mount Sinai Hospital, Suite 18-216, 600 University Ave, Toronto M5G 1X5, Canada

Full author information is available at the end of the article lung injury (ALI) survivors for physical morbidity. At discharge $36 \%$ had muscle weakness, with most improving within 12 months [7]; weakness was associated with impairments in physical function and quality of life that persisted at 24 months. Duration of bedrest during critical illness was consistently associated with weakness throughout the 24-month follow-up.

The current study reports the trajectory of physical decline of the ICAP cohort over 5 years, and risk factors for decline. In 193 ALI survivors three measures of physical status were evaluated annually: muscle strength using Medical Resource Council (MRC) sumscore, exercise capacity as reflected in the 6 Minute Walk Test (6MWT), and the physical functioning questions of the Short Form SF36 Health Survey. Approximately 1/3 of followup assessments were conducted in patients' homes. For each measure, a patient was considered 'declined' if the score decreased more than the 'Reliable Change Index' at follow-up. Over 5 years, 64 patients (33\%) died and were categorized as 'declined' in all three measures. Overall $86 \%$ of patients experienced death or decline in at least one measure; when decedents were excluded $69 \%$ experienced decline. In the multivariable model, older age was associated with declines in muscle strength, exercise capacity and physical function; and higher Charlson index was associated with declines in muscle strength and exercise capacity. APACHE II score, sedatives/opioids, and steroids were not associated with decline.

The study by Pfoh and her colleagues contributes valuable data and supports the findings of previous studies [1, $2,8-10]$. The strengths of this study are the large cohort, excellent patient retention, a long follow-up, detailed daily evaluation of critical illness and related treatment variables, and the use of standardized clinical evaluations using validated outcome measures.

While previous studies reported disability in survivors [1-3], Pfoh reported a composite outcome of death or disability. Classifying all patients who died during

\section{Springer}


follow-up as 'declined' provides a confusing picture of their outcomes, inflates the degree of disability in survivors, and wrongly implies that all deaths were related to sequelae of ARDS or critical illness. It is crucial to separate the outcomes of death and disability, and report any disability which occurs prior to death. Combining survivors and non-survivors does not serve to inform clinicians, patients or caregivers about expected disabilities and challenges that survivors will face. Patients and families want to know the likelihoods of dying in ICU, dying after they leave hospital, and returning to their pre-morbid functioning. Similarly, combining the stable/improved groups deprives stakeholders of important prognostic and potentially reassuring information. To address the limitations of the combined outcome, the authors conducted a sensitivity analysis which excluded decedents, in which only older age was a risk factor for physical decline, similar to the Towards RECOVER Study [3].

Another limitation of the current study, which the authors acknowledge, is the absence of a control group. This is not unique to this study, and we appreciate the challenges in identifying an appropriate control group. However, without a control group, it is unclear whether patients experienced 'normal' age-associated declines, or whether the long-term decline trajectory is indeed steeper in patients who develop critical illness or ARDS. The generalizability of these results may also be limited by patient enrolment occurring between 2004 and 2007, when ICU management was likely very different than current management, particularly relating to sedation, ventilation weaning, nutrition, steroids, and mobilization. Indeed, patients spent $35 \%$ of ICU days in coma, a median of 11 days on bed rest, and only $52 \%$ received physical therapy. Given advances in supportive ICU care over the last 15 years, it is possible that long-term outcomes of these patients may be better in 2016.

In contrast to the authors' conclusions, we propose a more positive perspective about their findings. Despite 'declines' in the individual measures, overall, patients showed improvements in all three measures of physical status. At 5 years, muscle strength and physical functioning appeared to be within normal range, and median $6 \mathrm{MWT}$ was $71 \%$ (IQR 59, 83) of predicted. Further, while MRC sumscore, 6MWT and SF-36 provide valuable information, they do not reflect a patient's ability to independently perform daily activities. Correspondingly, it is not clear whether the declines are clinically meaningful. Granular data describing what patients can and cannot do, and their degree of independence are most valuable. This is what we need to know about survivors of critical illness: can they independently dress, feed, step into a bathtub, stand from the toilet, climb stairs, and return to work? The ability to do these daily activities independently has a tremendous impact on the patient and caregivers, and dependence on others can be catastrophic for everyone.

The investigators identified age and Charlson index as significant risk factors for physical decline; and age alone in their sensitivity analysis of survivors. However, there are many other ICU- and post-discharge variables which could have a tremendous impact on physical health over 5 years, and are potentially modifiable. These include nutrition, delirium, rehabilitation, new illness, hospital readmission, return to work, functional status, psychological and cognitive dysfunction [11, 12], and caregiver/ family support. Patient frailty [13] may be an important predictor of outcome regardless of age or comorbid illness [14]. Further, assessment of muscle contractile capacity and not just muscle mass may be prognostically valuable [15].

Patients and their family members need to know about the cognitive and physical challenges they will face in their daily lives after surviving a debilitating critical illness. They need granular and detailed data about independent function-including walking, toileting, and returning to work. They want to know if they will get better, stay the same, or improve over time. This knowledge will allow them and their families to plan their lives and organize their support networks. For clinicians and investigators, knowledge of outcomes alone is not enough-we want to know how we can improve short- and long-term outcomes. Improving outcomes will require identification of modifiable patient and care-related risk factors across the care continuum-before, during and after ICU. It is time to move forward from describing longterm morbidity, to describing the biologic mechanisms of muscle and brain dysfunction, and hopefully designing interventions which reduce morbidity.

\section{Author details \\ ${ }^{1}$ Division of Critical Care Medicine, Department of Medicine and Interdepart- mental, Sinai Health System and University of Toronto, Toronto, ON, Canada. ${ }^{2}$ Nova Medical School, New University of Lisbon, Hospital de São Francisco Xavier, Lisbon, Portugal. ${ }^{3}$ Mount Sinai Hospital, Suite 18-216, 600 University Ave, Toronto M5G 1X5, Canada.}

Received: 27 September 2016 Accepted: 28 September 2016 Published online: 5 October 2016

\footnotetext{
References

1. Herridge MS, Cheung AM, Tansey C, Matte-Martyn A, Diaz-Granados N, Al-Saidi F, Cooper A, Guest C, Mazer D, Mehta S, Stewart T, Barr A, Bohn D, Cook D, Slutsky AS, The Canadian Critical Care Trials Group (2003) One year outcomes in survivors of the acute respiratory distress syndrome. New Engl J Med 348:683-693

2. Herridge MS, Tansey CM, Matte A, Tomlinson G, Diaz-Granados N, Cooper A, Guest CB, Mazer CD, Mehta S, Stewart TE, Kudlow P, Cook D, Slutsky AS,
} 
Cheung AM, The Canadian Critical Care Trials Group (2011) Functional disability five years after acute respiratory distress syndrome. N Engl J Med 364:1293-1304

3. Herridge MS, Chu LM, Matte A, Tomlinson G, Chan L, Thomas C, Friedrich JO, Mehta S, Lamontagne F, Levasseur M, Ferguson ND, Adhikari NK, Rudkowski JC, Meggison H, Skrobik Y, Flannery J, Bayley M, Batt J, Dos Santos C, Abbey SE, Tan A, Lo V, Mathur S, Parotto M, Morris D, Flockhart L, Fan E, Lee CM, Wilcox ME, Ayas N, Choong K, Fowler R, Scales DC, Sinuff T, Cuthbertson BH, Rose L, Robles P, Burns S, Cypel M, Singer L, Chaparro C, Chow CW, Keshavjee S, Brochard L, Hebert P, Slutsky AS, Marshall JC, Cook D, Cameron JI, RECOVER Program Investigators (Phase 1: towards RECOVER) and the Canadian Critical Care Trials Group (2016) The RECOVER Program: disability risk groups and one year outcome after $\geq 7$ days of mechanical ventilation. Am J Respir Crit Care Med 194:831-844

4. Cameron JI, Chu LM, Matte A, Tomlinson G, Chan L, Thomas C, Friedrich JO, Mehta S, Lamontagne F, Levasseur M, Ferguson ND, Adhikari NKJ, Rudkowski JC, Meggison H, Skrobik Y, Flannery J, Bayley M, Batt J, dos Santos C, Abbey SE, Tan A, Lo V, Mathur S, Parotto M, Morris D, Flockhart L, Fan E, Lee CM, Wilcox ME, Ayas N, Choong K, Fowler R, Rubenfeld GD, Scales DC, Sinuff T, Cuthbertson BH, Rose L, Robles P, Burns S, Cypel M, Singer L, Chaparro C, Chow C, Keshavjee S, Brochard L, Hebert P, Slutsky AS, Marshall JC, Cook D, Herridge MS for the RECOVER Program Investigators (Phase 1: towards RECOVER) and the Canadian Critical Care Trials Group (2016) The RECOVER Program: one-year outcomes in caregivers of critically ill patients mechanically ventilated for 7 days. N Engl J Med 374:1831-1841

5. Parotto M, Tomlinson G, Tansey CM, Matte A, Robles P, Mehta S, Guest C, Mazer D, Friedrich J, Slutsky A, Cook D, Cheung AM, Herridge MS (2016) Risk stratification of the Toronto ARDS cohort using RECOVER program disability groups. Am J Respir Crit Care Med 193:A1847

6. Pfoh ER, Wozniak AW, Colantuoni E, Dinglas VD, Mendez-Tellez PA, Shanholtiz C, Ciesla ND, Pronovost PJ, Needham DM (2016) Physical declines occurring after hospital discharge in ARDS survivors: a 5 year longitudinal study. Intensive Care Med 42:1557-1566. doi:10.1007/s00134-016-4530-1

7. Fan E, Dowdy DW, Colantuoni E, Mendez-Tellez PA, Sevransky JE, Shanholtz C, Himmelfarb CR, Desai SV, Ciesla N, Herridge MS, Pronovost PJ, Needham DM (2014) Physical complications in acute lung injury survivors: a two-year longitudinal prospective study. Crit Care Med 42:849-859
8. Combes A, Costa MA, Trouillet JL, Baudot J, Mokhtari M, Gibert C, Chastre $J$ (2003) Morbidity, mortality, and quality-of-life outcomes of patients requiring $>$ or $=14$ days of mechanical ventilation. Crit Care Med 31:1373-1381

9. Cuthbertson BH, Roughton S, Jenkinson D, Maclennan G, Vale L (2010) Quality of life in the five years after intensive care: a cohort study. Crit Care 14:R6

10. Hough CL, Caldwell ES, Cox CE, Douglas IS, Kahn JM, White DB, Seeley EJ, Bangdiwala SI, Rubenfeld GD, Angus DC, Carson SS, ProVent Investigators and the National Heart Lung and Blood Institute's Acute Respiratory Distress Syndrome Network (2015) Development and validation of a mortality prediction model for patients receiving 14 days of mechanical ventilation. Crit Care Med 43:2339-2345

11. Iwashyna TJ, Ely EW, Smith DM, Langa KM (2010) Long-term cognitive impairment and functional disability among survivors of severe sepsis. JAMA 304:1787-1794

12. Pandharipande PP, Girard TD, Jackson JC, Morandi A, Thompson JL, Pun BT, Brummel NE, Hughes CG, Vasilevskis EE, Shintani AK, Moons KG, Geevarghese SK, Canonico A, Hopkins RO, Bernard GR, Dittus RS, Ely EW, BRAIN-ICU Study Investigators (2013) Long-term cognitive impairment after critical illness. N Engl J Med 369:1306-1316

13. Rockwood K, Song X, MacKnight C, Bergman H, Hogan DB, McDowell I, Mitnitski A (2005) A global clinical measure of fitness and frailty in elderly people. CMAJ 173:489-495

14. Heyland DK, Garland A, Bagshaw SM, Cook D, Rockwood K, Stelfox HT, Dodek P, Fowler RA, Turgeon AF, Burns K, Muscedere J, Kutsogiannis J, Albert M, Mehta S, Jiang X, Day AG (2015) Recovery after critical illness in patients aged 80 years or older: a multi-center prospective observational cohort study. Intensive Care Med 41:1911-1920

15. Dos Santos C, Hussain SN, Mathur S, Picard M, Herridge M, Correa J, Bain A, Guo Y, Advani A, Advani SL, Tomlinson G, Katzberg H, Streutker CJ, Cameron JI, Schols A, Gosker H, Batt J, MEND ICU Group, RECOVER Program Investigators, Canadian Critical Care Translational Biology Group (2016) Mechanisms of chronic muscle wasting and dysfunction after an intensive care unit stay: a pilot study. Am J Respir Crit Care Med 194:821-830 